\title{
Dispersion of single-walled carbon nanotubes in an aqueous medium by using a cyclic copolymer
}

Ning Zhang ${ }^{1}$, Di Zhou ${ }^{2}$, Nianchen Zhou ${ }^{1}$, Zhengbiao Zhang ${ }^{1}$, and Xiulin Zhu ${ }^{1} *$

\begin{abstract}
A cyclic copolymer, poly(methoxy-PEG acrylate-co-3-(4-benzoylphenoxy) propyl acrylate), was successfully synthesized by $\mathrm{Cu}(0)$-mediated controlled radical polymerization and $\mathrm{Cu}(\mathrm{I})$-catalyzed azide-alkyne cycloaddition "click" chemistry. The self-assembly behaviors of the linear and cyclic copolymers were investigated. Subsequently, the linear and cyclic copolymers were used to disperse the single-walled carbon nanotubes (SWCNTs) in an aqueous medium. The results showed that cyclic copolymers could form uniformly stable, spherical morphologies by self-assembly more easily than their linear counterparts under the same conditions. Cyclic copolymers were also found to better disperse SWCNTs, thereby extending the applications of SWCNTs in an aqueous medium.
\end{abstract}

Keywords: cyclic copolymer, self-assembly, SWCNTs 


\section{Introduction}

The discovery of carbon nanotubes (CNTs) and CNT-based materials has attracted increasing attention because of their wide range of applications. To increase the use of CNTs, surfactants are highly desired because of their abilities to interact with CNTs through noncovalent interactions such as ionic bonds to improve the dispersion of CNTs $[1,2]$. The progress of dispersing CNTs by using surfactants has reached a new plateau in recent years because of its unique advantage. A remarkable achievement in this effort is dispersion by using the ionic surfactant sodium dodecylbenzene sulfonate (NaDDBS) reported by Yodh and colleagues [3]. When the concentration of the surfactant was above the critical micelle concentration (CMC), it was adsorbed onto the surface of the CNTs and self-organized into micelles. The mechanism of the surfactant-assisted aqueous dispersion of CNTs was also illustrated by a few other researchers [4-6]. Three most possible configurations were proposed: hemispherical micelles, cylindrical micelles, and randomly adsorbed molecules.

Because of the distinct structure of CNTs, $\pi-\pi$ reaction was used to stabilize them [7]. For instance, a molecule with a $\pi$-conjugated backbone built from aromatic thiophene and dialkoxyphenylene units and substituted imidazolium groups was designed to obtain ultra-stable, single-walled carbon nanotube (SWCNT) dispersion in an aqueous medium [8]. The peptide aptamer IFRLSWGTYFS exhibited a high dispersion capability below the CMC. From the results of isothermal titration calorimetry and molecular dynamic simulations, it was observed that the effective binding capability of the peptide was because of the $\pi-\pi$ interaction between the aromatic groups of the peptide aptamer and the side walls of SWCNTs [9]. Amphiphilic block copolymers were used to wrap and disperse CNTs in aqueous medium $[6,10,11]$. The wrapping and dispersion efficiencies were affected by the 
structure of the copolymers (chemical composition, molecular weight, and hydrophilic/hydrophobic balance). Aromatic groups such as benzene [12] or thiophene $[13,14]$ were introduced into the amphiphilic block copolymers to disperse CNTs more effectively by the strong $\pi-\pi$ interactions with CNTs.

The self-assembly behaviours of the cyclic polymers are different from those of the linear polymers $[15,16]$. Several studies compared the aggregation phenomenon between the linear and cyclic polymers [17-26] and found that the cyclic amphiphilic copolymers possessed their unique self-assembly behaviours and improved physical properties as well. Impressive micelles with a flower-like morphology were formed from amphiphilic block copolymers [18]. Previously, the facile synthesis and topological effects on the self-assembly and photoisomerization of polymers containing the azobenzene group $[27,28]$ and on the self-assembly of amphiphilic macrocycles containing polymeric liquid crystal grafts in solution [29] were reported by our group. There are few publications reporting the interaction between the cyclic polymers and CNTs. Different methods to prepare cyclic polymers were proposed [30-34]. Herein, we synthesized a cyclic copolymer, poly(methoxy-PEG acrylate-co-3-(4-benzoylphenoxy) propyl acrylate) (poly(PEGA-co-BPPA)), containing a short PEG side chain and the benzophenone group through $\mathrm{Cu}(0)$-mediated controlled radical polymerization [35] and $\mathrm{Cu}(\mathrm{I})$-catalyzed azide-alkyne cycloaddition (CuAAC) "click" chemistry [36, 37]. The self-assembly of cyclic copolymers and its linear precursors was analysed systematically. The linear and cyclic copolymers were used to disperse SWCNTs in an aqueous medium. The benzophenone group tends to aggregate together and better interact with the SWCNTs through the $\pi-\pi$ reactions, whereas the short PEG chains maintain the dispersion of SWCNTs more stable in the aqueous medium. The results showed that the cyclic 
copolymers self-assembled into uniformly stable, spherical structures in the aqueous medium and could disperse SWCNTs better than their linear precursors.

\section{Experimental}

\subsection{Materials}

Methoxy-PEG acrylate (PEGA; average $M n \sim 480$ ) was purchased from Sigma-Aldrich. The inhibitors from PEGA were removed by passing it through a neutral alumina column. 4-Hydroxybenzophenone (>99\% pure), Nile Red ( $>99.5 \%$ pure), and sodium azide $\left(\mathrm{NaN}_{3} ;>99.5 \%\right.$ pure $)$ were purchased from Sigma-Aldrich. 3-Bromo-1-propanol, Alfa Aesar (98\% pure), acryloyl chloride, triethylamine, and copper powder $(\mathrm{Cu})$ were purchased from Energy Chemical. Tris(2-dimethylaminoethyl)amine $\left(\mathrm{ME}_{6} \mathrm{TREN}\right)$ and $\mathrm{N}, \mathrm{N}, \mathrm{N}^{\prime}, \mathrm{N}^{\prime \prime}, \mathrm{N}^{\prime \prime \prime}-$ pentamethyldiethylenetriamine (PMDETA) were purchased from J\&K Scientific Ltd. Potassium carbonate, sodium sulfate, and all solvents were purchased from Sinopharm Chemical Reagent Co. Ltd. Copper(I) bromide (CuBr, Adamas) was freshly purified by stirring in acetic acid overnight and then was washed with acetone and dried in vacuum. SWCNTs (PT25) were purchased from Nano-C.

\subsection{Characterization}

A recycling preparative SEC (Japan Analytical Industry Co., Ltd.) system equipped with differential refractive index detector was used to refine the crude copolymers. The dried crude copolymers were dissolved in tetrahydrofuran (THF) at a concentration of $200 \mathrm{mg} / \mathrm{mL}$ and filtered through a $0.45-\mu \mathrm{m}$ PTFE syringe filter prior to injection. The preparative SEC flow rate was maintained at $6 \mathrm{~mL} / \mathrm{min}$, and $\mathrm{THF}$ was used as the eluent. The target fraction was collected manually and determined using the TOSOH HLC-8320 SEC equipped with refractive index and UV detectors 
as described above. The number-average molecular weight $(M n)$ and the molecular weight distribution $(M w / M n)$ of the polymers were determined using the SEC (TOSOH HLC-8320), which was equipped with a refractive index detector (TOSOH), and using a TSKgel guard column SuperMP-N $(4.6 \times 20 \mathrm{~mm})$ and two TSKgel Supermultipore HZ-N $(4.6 \times 150 \mathrm{~mm}, 3-\mu \mathrm{m}$ bead size $)$ with a measurable molecular weight ranging from $5 \times 10^{2}$ to $1.9 \times 10^{5} \mathrm{~g} / \mathrm{mol}$. THF was used as the eluent at a flow rate of $0.35 \mathrm{~mL} / \mathrm{min}$ at $42^{\circ} \mathrm{C}$. The SEC samples were injected using a TOSOH plus autosampler and calibrated with PMMA standards purchased from TOSOH.

The ${ }^{1} \mathrm{H}$ NMR and ${ }^{13} \mathrm{C}$ NMR spectroscopies were recorded on a Bruker $300-\mathrm{MHz}$ nuclear magnetic resonance instrument by using tetramethylsilane (TMS) as an internal standard. The FT-IR spectra were obtained on a Bruker TENSOR-27 FT-IR spectrometer by mixing the polymers with $\mathrm{KBr}$ tablets. The UV-Vis spectra were recorded on a Shimadzu UV-3150 spectrophotometer (Shimadzu China, Shanghai, China). The hydrodynamic diameter $\left(D_{h}\right)$ of spherical self-assembled morphologies were measured by dynamic light scattering (DLS) using Brookhaven's NanoBrook 90Plus PALS instrument at $25^{\circ} \mathrm{C}$ at a scattering angle of $90^{\circ}$.

The morphologies of the copolymers, SWCNTs, and copolymers/SWCNTs were measured using a transmission electron microscope (TEM) (HITACHI HT7700) at a voltage of $120 \mathrm{kV}$. The samples were prepared by placing $10 \mu \mathrm{L}$ of the self-assembled copolymer solution onto a carbon coated copper grid, and after $60 \mathrm{~s}$, the superfluous solution was absorbed using a piece of filter paper. The same procedure was repeated three times, and the grid was left to dry overnight. The surface morphologies were measured by atomic force microscope (AFM) with a tapping mode (Veeco Instruments Inc., Nanoscope IV) and the self-assembled mixture solutions were diluted to 200 times and dropped onto a precleaned silicon wafer. 


\subsection{Synthesis of linear poly(PEGA-co-BPPA)}

The specific procedure for the synthesis of the initiator propargyl 2-bromoisobutyrate (PBIB) and monomer 3-(4-benzoylphenoxy) propyl acrylate (BPPA) is shown in the supporting information. The linear poly(PEGA-co-BPPA) was prepared by following the typical procedure: PEGA $(1.0 \mathrm{~g}, 2.08 \mathrm{mmol})$, BPPA (64.7 mg, $0.21 \mathrm{mmol}), \mathrm{Cu}(2.2 \mathrm{mg}, 0.035 \mathrm{mmol}), \mathrm{ME}_{6}$ TREN (7.8 mg, $\left.0.07 \mathrm{mmol}\right)$, PBIB (14.2 mg, $0.069 \mathrm{mmol}$ ), and $\mathrm{N}, \mathrm{N}^{\prime}$-dimethylformamide (DMF, $2 \mathrm{~mL}$ ) were placed in a 5-mL flask and degassed by freeze-pump-thaw cycles for three times. The flask was filled with $\mathrm{N}_{2}$ and transferred into a thermostat at $25^{\circ} \mathrm{C}$. After $2 \mathrm{~h}$, the mixture was diluted with $2 \mathrm{~mL}$ of $\mathrm{DMF}$ and precipitated in a large amount of cold diethyl ether, and the copolymer was obtained by centrifugation. The product was washed using ethylenediaminetetraacetic acid (EDTA) disodium solution (DMSO) and extracted by dichloromethane. After removing the solvent and drying in a vacuum oven at $25^{\circ} \mathrm{C}$ overnight, purified linear copolymer was obtained and refined by recycling preparative SEC (0.89 g, yield: $89 \%)$.

\subsection{Synthesis of cyclic poly(PEGA-co-PBPPA)}

To obtain cyclic poly(PEGA-co-PBPPA), the end group of linear poly(PEGA-co-BPPA) was modified to $-\mathrm{N}_{3}$ group by sodium azide as follows: the linear copolymer poly(PEGA-co-BPPA) $(0.89 \mathrm{~g}, 0.087 \mathrm{mmol})$ was dissolved in 20 $\mathrm{mL}$ of ultrapure water, and $\mathrm{NaN}_{3}(283.6 \mathrm{mg}, 4.35 \mathrm{mmol})$ was added. The solution was stirred overnight at $25^{\circ} \mathrm{C}$ before extraction by dichloromethane and precipitation into cold diethyl ether, and the linear poly(PEGA-co-BPPA)- $\mathrm{N}_{3}$ was obtained (0.73 g, yield: $82 \%$ ). Subsequently, in a three-necked flask, $800 \mathrm{~mL}$ of anaerobic toluene was added, and PMDETA (260.4 mg, $1.5 \mathrm{mmol})$ and $\mathrm{CuBr}(140.6 \mathrm{mg}, 1 \mathrm{mmol})$ were then added into the flask under Ar. The linear poly(PEGA-co-BPPA)- $\mathrm{N}_{3}(100 \mathrm{mg}, 0.01$ 
mmol) dissolved in $20 \mathrm{~mL}$ of toluene was introduced through the syringe pump slowly (injection rate: $0.5 \mathrm{~mL} / \mathrm{h}$ ) for $40 \mathrm{~h}$ at $60^{\circ} \mathrm{C}$. After completion of this procedure, the mixture was stirred for another $48 \mathrm{~h}$. Then, azide resin $(100 \mathrm{mg})$ was added, and after $12 \mathrm{~h}$, the mixture was cooled to room temperature and was purified using an EDTA-2Na column to remove the metal salt and the azide resin. After removing most solvents by evaporation, the residue was dissolved in saturated EDTA-2Na solution to allow the rest of the metal salt to precipitate. The final product was extracted by dichloromethane three times and dried by $\mathrm{Na}_{2} \mathrm{SO}_{4}$. The purified copolymer was obtained by precipitating in cold diethyl ether and dried in a vacuum oven overnight at $25^{\circ} \mathrm{C}(0.059 \mathrm{~g}$, yield: $59 \%)$.

\subsection{Self-assembly of linear and cyclic copolymers}

The self-assembly behaviours of linear poly(PEGA-co-BPPA) and cyclic poly(PEGA-co-BPPA) were investigated according to the previous studies [28, 29, 38]. The CMCs of the linear and cyclic copolymers were acquired on Nile Red fluorescence, and the data are presented in Figure S9 (supporting information). A typical self-assembly solution was prepared by slowly adding $\mathrm{H}_{2} \mathrm{O}$ into the DMF solution with a polymer concentration of $1.5 \mathrm{mg} / \mathrm{mL}$. The polymer DMF solution was filtered through a PTFE filter with $0.22-\mu \mathrm{m}$ pore size to remove any dusts to obtain the stock solution. Then, $1 \mathrm{~mL}$ of $\mathrm{H}_{2} \mathrm{O}$ was added slowly at the rate of $0.1 \mathrm{~mL} / \mathrm{h}$ through the syringe pump to the above solution while stirring (500 rpm), and the mixture was stirred overnight at room temperature. To obtain stable micelles, DMF was removed by dialyzing the solution against deionized water for $48 \mathrm{~h}$. All these steps were required to be performed in dark.

\subsection{Dispersion of SWCNTs by linear and cyclic copolymers}

Purified SWCNTs were dispersed in $\mathrm{H}_{2} \mathrm{O}$ by ultrasonic treatment for $1 \mathrm{~h}$ under 
$800 \mathrm{~W}$ at $0^{\circ} \mathrm{C}$, resulting in a $0.01 \%$ SWCNT (wt $\%$ ) suspension for further use [1, 39-41]. Two methods were employed to disperse SWCNTs. Method I: Linear or cyclic copolymers $(0.5 \mathrm{mg})$ were dissolved in $5 \mathrm{~mL}$ of DMF in a bottle, and the equivalent SWCNT suspension previously prepared was then added and stirred for $2 \mathrm{~h}$. DMF was removed by dialyzing the solution against deionized water for another $48 \mathrm{~h}$ to allow copolymer/SWCNT dispersion. Method II: Ten millilitres of the SWCNT suspension and $667 \mu \mathrm{L}$ of the copolymer self-assembly solution were mixed and followed by ultrasonic treatment for $20 \mathrm{~min}$ at $0^{\circ} \mathrm{C}$. DMF was removed by dialyzing the solution against deionized water for another $48 \mathrm{~h}$ to allow copolymer assembly/SWCNT dispersion.

\section{Results and discussion}

3.1. Characterizations of linear poly(PEGA-co-BPPA) and cyclic $\operatorname{poly}(P E G A-c o-B P P A)$

The synthetic routes of linear poly(PEGA-co-BPPA) and cyclic poly(PEGA-co-BPPA) are shown in Scheme 1. The functional monomer BPPA contains benzophenone, which could produce free radicals under strong lights or high temperature. Therefore, the $\mathrm{Cu}(0)$-mediated controlled radical polymerization was employed as a convenient living free radical polymerization at room temperature. Furthermore, it could be conducted with a fast reaction rate and high functionality of the end group. The functional initiator PBIB was synthesized to introduce both ethynyl and bromine end groups in the copolymers. The bromine end group of the obtained linear copolymer was reacted with $\mathrm{NaN}_{3}$ to result in an azide end group for future cyclization. The cyclic copolymer was successfully produced by CuAAC reaction, and the cyclization process was confirmed by comprehensive 
characterization including SEC, FT-IR, and ${ }^{1} \mathrm{H}-\mathrm{NMR}$.

(Scheme 1 is here)

The polymerization was performed at a feed ratio of $[\mathrm{PEGA}]_{0} /[\mathrm{BPPA}]_{0} /[\mathrm{PBIB}]_{0} /[\mathrm{Cu}]_{0} /\left[\mathrm{ME}_{6} \mathrm{TREN}\right]_{0}=30: 3: 1: 0.5: 1$, and the linear poly(PEGA-co-BPPA) was obtained with a molecular weight of $M n=10,200 \mathrm{~g} / \mathrm{mol}$ measured by SEC. After cyclization, the elution curve of cyclic poly(PEGA-co-BPPA) entirely shifted toward the long retention time as expected, when compared with that of linear poly(PEGA-co-BPPA) as shown in Figure 1; this was because of the decreased hydrodynamic volume of cyclic poly(PEGA-co-BPPA) upon transformation [42], which provides a clear evidence of its successful preparation.

(Figure 1 is here)

(Figure 2 is here)

FT-IR provided further evidence for the cyclization shown in Figure 2. The successful installation of azide end groups was reflected by the $\mathrm{N}=\mathrm{N}=\mathrm{N}$ antisymmetric stretch at $\sim 2100 \mathrm{~cm}^{-1}$, and the successful ring closure was reflected by the complete disappearance of the characteristic azide signal because of the formation of the triazole group. These results convincingly verify the processes of copolymer conversions.

Linear poly(PEGA-co-BPPA), linear poly(PEGA-co-BPPA)-N $\mathrm{N}_{3}$, and cyclic poly(PEGA-co-BPPA) were characterized by ${ }^{1} \mathrm{H}-\mathrm{NMR}$ as shown in Figure 3. The average ratio of PEGA and BPPA units in the copolymers is 12:1 as calculated from 
the integral value, which was almost the same as the feed ratio. After azidation, the methyne proton signals at the end of L-poly(PEGA-co-BPPA)-Br at 4.82-5.10 ppm (peak 1 in Figure 3a) disappeared and shifted to $4.10-4.40 \mathrm{ppm}$, which indicates the complete end group transformation from bromo to azido group as shown in Figure 3(b). After the cyclization by "CuAAC" reaction, a new resonance peak at 5.09-5.25 ppm appeared, which is because of the chemical shifts of methylene protons (p) and methyne protons (q) adjacent to the newly formed triazole group as shown in Figure 3(c). Another evidence was the disappearance of the alkyne signals at $2.57 \mathrm{ppm}$ (a) as shown in Figure 3(c) because the alkynyl ring transformed to triazole ring after the cyclization. Considering all these results together, we confirm the successful production of cyclic poly(PEGA-co-BPPA). In addition, to confirm the successful preparation of linear poly(PEGA-co-BPPA) and cyclic poly(PEGA-co-BPPA), matrix-assisted laser desorption/ionization time of flight (MALDI-TOF) mass spectrometry was used (supporting information).

(Figure 3 is here)

\subsection{Self-assembly of linear poly(PEGA-co-BPPA) and cyclic poly(PEGA-co-BPPA)}

According to the structure of linear poly(PEGA-co-BPPA) and cyclic poly(PEGA-co-BPPA), the main chain and BPPA units are hydrophobic, whereas the side PEG chain is hydrophilic. The presence of hydrophobic and hydrophilic chains is a prerequisite for the copolymers to self-assemble into aggregates in different solvents [43]. The self-assembly behaviours of linear poly(PEGA-co-BPPA) and cyclic poly(PEGA-co-BPPA) were examined by DLS and TEM. As shown in Figure $4, \mathrm{D}_{\mathrm{h}}$ of spherical aggregates of cyclic poly(PEGA-co-BPPA) $\left(D_{h}=29.36\right)$ measured by 
DLS was significantly smaller than that of the linear counterpart $\left(D_{h}=133.93\right)$ under almost the same conditions. The distribution of the cyclic copolymer was narrower than that of the linear copolymer, which indicates that the spherical aggregates of the cyclic copolymer were more uniform than those of the linear copolymer. The TEM images in Figure 5 present that the micelles from cyclic poly(PEGA-co-BPPA) clearly appeared as individual spherical objects with a diameter of about $30-50 \mathrm{~nm}$ in the aqueous medium, which agrees closely with the data observed in DLS. Surprisingly, the micelles formed by the linear copolymer, however, were irregular and entangled. These phenomena were confirmed by repeating the experiments, which could account for the differences between the cyclic and linear copolymers in structure, i.e. after the cyclization, the hydrophobic chains were well concentrated in the cyclic copolymer in comparison with those in the linear copolymer. According to the critical packing parameter theory, the hydrophobic/hydrophilic balance of an amphiphilic block copolymer determines the morphology of the self-assembly [15]. It is also presumably explained by the fact that the linear polymer had a free chain end bridged between the micelles $[44,45]$.

(Figure 4 is here)

(Figure 5 is here)

3.3. Dispersion of SWCNTs in an aqueous medium by linear poly(PEGA-co-BPPA) and cyclic poly(PEGA-co-BPPA)

The difficulty of dispersing CNTs has become one of the most important issues that limits their applications. Therefore, the use of cyclic copolymers as a dispersant has strongly attracted our interests because of their unique self-assembly behaviours as 
discussed above. Their dispersing efficiencies were investigated by UV-Vis, TEM, and AFM. During our experiment, it was rather interesting to find that when we compared the colours of undispersed SWCNTs with those of L-copolymer/SWCNT, C-copolymer/SWCNT, L-copolymer assembly/SWCNT, and C-copolymer assembly/SWCNT suspensions under identical conditions, all the SWCNT suspensions containing copolymers were significantly darker than the control SWCNTs, as presented in Figure 6. This indicates the high concentration of SWCNTs in suspensions. We used UV-Vis spectroscopy to evaluate the aqueous dispersion, the findings of which are provided in Figure 6. The copolymer suspensions consisting of SWCNTs exhibited strong absorption at $253 \mathrm{~nm}$ [46, 47]. Nevertheless, linear poly(PEGA-co-BPPA) and cyclic poly(PEGA-co-BPPA) had weak absorption at this wavelength (see supporting information). The absorption of C-copolymer suspension was stronger than that of L-copolymer suspension, which implies that the UV absorption of aqueous SWCNT solution essentially depended on the number of nanotubes homogeneously dispersed in the aqueous medium and that the dispersion efficiency of the C-copolymer suspensions was higher than that of the L-copolymer suspensions. It was also found that no obvious absorption peak in pure SWCNTs was observed because of the poor dispersion abilities of SWCNTs in water. In addition, we specifically traced the SWCNTs' dispersion. After 1 week, the concentrations of pure SWCNTs dramatically decreased approximately 50\%, while those of copolymer/SWCNTs and copolymer assembly/SWCNTs decreased less than $12 \%$. Another interesting observation was that the concentrations of copolymer/SWCNTs and copolymer assembly/SWCNTs remained stable even after 3 days, whereas those of the SWCNT suspension decreased. These results show that both linear and cyclic copolymers could stabilize SWCNT suspension and that the dispersion ability of the 
cyclic copolymers in the aqueous medium is higher than that of the linear copolymers.

(Figure 6 is here)

The morphological details of these self-assemblies were clearly depicted by TEM images and AFM images. SWCNTs were extremely difficult to disperse into the aqueous medium even under sonication and with smooth SWCNT aggregator surface, as shown in Figure 7. However, the aggregators of copolymer/SWCNTs and copolymer assembly/SWCNTs apparently reduced because copolymers covered the surface of SWCNTs as shown in Figure 7a-d. Some stable self-assembly of cyclic copolymers that covered the surface of SWCNTs can be obviously seen from Figure $7 \mathrm{~d}$. The diameters of the spherical morphologies, which covered the surface of the SWCNTs, were approximately $20-30 \mathrm{~nm}$, consistent with the data in Figure $5 \mathrm{~b}$. It is highly challenging to determine how the amphiphilic molecules organized on the CNTs. From our results, it was shown that the molecules were adsorbed on the surface of SWCNTs as spherical micelles. These morphologies were further investigated by AFM (Figure 8). The images in Figure 8 show that the diameters of SWCNTs, L-copolymer/SWCNTs, C-copolymer/SWCNTs, L-copolymer assembly/SWCNTs, and C-copolymer assembly/SWCNTs were approximately 111, 91, 64, 77, and $28 \mathrm{~nm}$, respectively. The relatively small diameters of C-copolymer/SWCNTs and C-copolymer assembly/SWCNTs suggest that the C-copolymer assembly could easily break the aggregators of SWCNTs because of concentrated hydrophobic chains, thereby allowing the SWCNTs to be better dispersed. 
(Figure 7 is here)

(Figure 8 is here)

To disperse SWCNTs in an aqueous medium using a cyclic copolymer, we chose two different methods as described in the experimental section. Combining the images of TEM in Figure 7 and AFM in Figure 8 with UV-Vis absorption spectra in Figure 6, we put forward the schematic illustration models (shown in Figure 9) of the dispersion of SWCNTs using a cyclic copolymer for the two different methods. The SWCNTs can be randomly adsorbed by cyclic copolymers (Figure 9(a)) according to method I or covered with spherical micelles (Figure 9(b)) according to method II. Figure 9(a) depicts that the hydrophobic main chains of the cyclic copolymers were randomly adsorbed on the surface of SWCNTs, while the hydrophilic side chains associated with water for dissolution. The schematic illustration model in Figure 9(b) shows that regular spherical micelles covered the surface of SWCNTs under the force of strong $\pi-\pi$ interactions. From Figures $7(d)$ and $8(d)$, we could clearly confirm that the spherical micelles covered the surface of SWCNTs.

(Figure 9 is here)

\section{Conclusions}

In summary, we synthesized the cyclic copolymer poly(PEGA-co-BPPA) containing short PEG side chain and benzophenone group by $\mathrm{Cu}(0)$-mediated controlled radical polymerization and $\mathrm{Cu}(\mathrm{I})$-catalyzed azide-alkyne cycloaddition (CuAAC) "click" chemistry. Both linear and cyclic copolymers were used to disperse the SWCNTs in the aqueous medium. The results indicate that both linear and cyclic 
copolymers could stabilize SWCNT suspension and that the dispersion ability of cyclic copolymers in the aqueous medium is higher than that of the linear copolymers. The DLS and TEM results showed that the uniformly stable self-assembled spherical morphologies could be obtained from cyclic copolymers. The TEM and AFM results showed that the C-copolymer assembly could cover the surface of SWCNTs and disperse them effectively.

\section{Acknowledgment}

This work was supported by the National Science Foundation of China (21234005), the Jiangsu Key Laboratory of Advanced Functional Polymer Design and Application (Soochow University, No. KJS1407), and the Natural Science Foundation of the Jiangsu Higher Education Institutions (No.15KJB430001). The authors specially thank Dr. Yoshihiro Ito and Dr. Masuki Kawamoto (RIKEN, Japan) who devoted considerable time and effort for their comments on the discussion.

\section{References}

[1] R.M.F. Fernandes, B. Abreu, B. Claro, M. Buzaglo, O. Regev, I. Furo, E.F. Marques, Langmuir 31(40) (2015) 10955-10965.

[2] B. Kumar, Y.T. Park, M. Castro, J.C. Grunlan, J.F. Feller, Talanta 88 (2012) 396-402.

[3] M.F. Islam, E. Rojas, D.M. Bergey, A.T. Johnson, A.G. Yodh, Nano Lett 3(2) (2003) 269-273.

[4] K. Yurekli, C.A. Mitchell, R. Krishnamoorti, J Am Chem Soc 126(32) (2004) 9902-9903.

[5] H. Wang, Curr Opin Colloid In 14(5) (2009) 364-371.

[6] M.J. O'Connell, P. Boul, L.M. Ericson, C. Huffman, Y.H. Wang, E. Haroz, C. Kuper, J. Tour, K.D. Ausman, R.E. Smalley, Chem Phys Lett 342(3-4) (2001) 265-271. 
[7] F. Ernst, T. Heek, A. Setaro, R. Haag, S. Reich, J Phys Chem C 117(2) (2013) $1157-1162$.

[8] S.L. Nogueira, S.K. Sahoo, T. Jarrosson, F. Serein-Spirau, J.P. Lere-Porte, E.A. Moujaes, A. Marletta, A.P. Santos, C. Fantini, C.A. Furtado, R.A. Silva, J Colloid Interf Sci 464 (2016) 117-125.

[9] Z. Li, T. Kameda, T. Isoshima, E. Kobatake, T. Tanaka, Y. Ito, M. Kawamoto, Langmuir 31(11) (2015) 3482-3488.

[10] F. Meyer, J.M. Raquez, P. Verge, I.M. de Arenaza, B. Coto, P. Van Der Voort, E. Meaurio, B. Dervaux, J.R. Sarasua, F. Du Prez, P. Dubois, Biomacromolecules 12(11) (2011) 4086-4094.

[11] C. Semaan, G. Pecastaings, M. Schappacher, A. Soum, Polym Bull 68(2) (2012) $465-481$.

[12] G.F. Bass, M.S. Colt, A.D. Chavez, G.X. DeHoe, T.P. Formal, C.P. Seaver, K. Kha, B.A. Kelley, G.E. Scott, C.E. Immoos, P.J. Costanzo, Polymer 72 (2015) 301-306.

[13] J.H. Zou, S.I. Khondaker, Q. Huo, L. Zhai, Adv Funct Mater 19(3) (2009) 479-483.

[14] S. Sarkar, J.H. Zou, J.H. Liu, C.Y. Xu, L.A. An, L. Zhai, Acs Appl Mater Inter 2(4) (2010) 1150-1156.

[15] R.J. Williams, A.P. Dove, R.K. O'Reilly, Polym Chem-Uk 6(16) (2015) 2998-3008.

[16] T. Yamamoto, Y. Tezuka, Soft matter 11(38) (2015) 7458-7468.

[17] S. Honda, M. Koga, M. Tokita, T. Yamamoto, Y. Tezuka, Polym Chem-Uk 6(22) (2015) 4167-4176.

[18] S. Honda, T. Yamamoto, Y. Tezuka, J Am Chem Soc 132(30) (2010) 10251-10253.

[19] R. Borsali, E. Minatti, J.L. Putaux, M. Schappacher, A. Deffieux, P. Viville, R. Lazzaroni, T. Narayanan, Langmuir 19(1) (2003) 6-9.

[20] D.E. Lonsdale, M.J. Monteiro, J Polym Sci Pol Chem 49(21) (2011) 4603-4612.

[21] H. Iatrou, N. Hadjichristidis, G. Meier, H. Frielinghaus, M. Monkenbusch, Macromolecules 35(14) (2002) 5426-5437.

[22] C.U. Lee, T.P. Smart, L. Guo, T.H. Epps, D.H. Zhang, Macromolecules 44(24) (2011) 9574-9585. 
[23] L.W. Li, J.X. Yang, J.F. Zhou, Macromolecules 46(7) (2013) 2808-2817.

[24] B.Y. Zhang, H. Zhang, Y.J. Li, J.N. Hoskins, S.M. Grayson, Acs Macro Lett 2(10) (2013) 845-848.

[25] K. Heo, Y.Y. Kim, Y. Kitazawa, M. Kim, K.S. Jin, T. Yamamoto, M. Ree, Acs Macro Lett 3(3) (2014) 233-239.

[26] E. Baba, T. Yatsunami, Y. Tezuka, T. Yamamoto, Langmuir 32(40) (2016) 10344-10349.

[27] Y.D. Sun, Z. Wang, Y.W. Li, Z.B. Zhang, W. Zhang, X.Q. Pan, N.C. Zhou, X.L. Zhu, Macromol Rapid Comm 36(14) (2015) 1341-1347.

[28] Y. Cai, J.J. Lu, F. Zhou, X.J. Zhou, N.C. Zhou, Z.B. Zhang, X.L. Zhu, Macromol Rapid Comm 35(9) (2014) 901-907.

[29] F. Zhou, Z.B. Zhang, G.Q. Jiang, J.J. Lu, X.F. Chen, Y.W. Li, N.C. Zhou, X.L. Zhu, Polym Chem-Uk 7(16) (2016) 2785-2789.

[30] E.M. Carnicom, E.S. Tillman, React Funct Polym 80 (2014) 9-14.

[31] A. Bunha, P.F. Cao, J.D. Mangadlao, R.C. Advincula, React Funct Polym 80 (2014) 33-39.

[32] S.Y. Long, Q.Q. Tang, Y. Wu, L.X. Wang, K. Zhang, Y.M. Chen, React Funct Polym 80 (2014) $15-20$

[33] P. Hodge, React Funct Polym 80 (2014) 21-32.

[34] N. Sugai, H. Heguri, K. Ohta, Q.Y. Meng, T. Yamamoto, Y. Tezuka, J Am Chem Soc 132(42) (2010) 14790-14802.

[35] V. Percec, T. Guliashvili, J.S. Ladislaw, A. Wistrand, A. Stjerndahl, M.J. Sienkowska, M.J. Monteiro, S. Sahoo, J Am Chem Soc 128(43) (2006) 14156-14165.

[36] B.A. Laurent, S.M. Grayson, J Am Chem Soc 128(13) (2006) 4238-4239.

[37] H.C. Kolb, M.G. Finn, K.B. Sharpless, Angew Chem Int Edit 40(11) (2001) 2004-2021.

[38] L.F. Zhang, A. Eisenberg, J Am Chem Soc 118(13) (1996) 3168-3181.

[39] L.M. He, Q. Jiang, J.K. Chen, M. Sun, S. Yuan, D.Q. Han, X.Y. Lu, Y. Zhao, Mater Lett 134 (2014) 194-197. 
[40] S. Badaire, P. Poulin, M. Maugey, C. Zakri, Langmuir 20(24) (2004) 10367-10370.

[41] K.G. Dassios, P. Alafogianni, S.K. Antiohos, C. Leptokaridis, N.M. Barkoula, T.E. Matikas, J Phys Chem C 119(13) (2015) 7506-7516.

[42] Z.F. Jia, M.J. Monteiro, J Polym Sci Pol Chem 50(11) (2012) 2085-2097.

[43] X.F. Ji, S.Y. Dong, P.F. Wei, D.Y. Xia, F.H. Huang, Adv Mater 25(40) (2013) $5725-5729$.

[44] C.U. Lee, T.P. Smart, L. Guo, T.H. Epps, 3rd, D. Zhang, Macromolecules 44(24) (2011) 9574-9585.

[45] B. Zhang, H. Zhang, Y. Li, J.N. Hoskins, S.M. Grayson, ACS macro letters 2(10) (2013) 845-848.

[46] L.Q. Jiang, L. Gao, J. Sun, J Colloid Interf Sci 260(1) (2003) 89-94.

[47] C.Y. Tang, G.C. Long, X. Hu, K.W. Wong, W.M. Lau, M.K. Fan, J. Mei, T. Xu, B. Wang, D. Hui, Nanoscale 6(14) (2014) 7877-7888. 


\section{Captions}

Scheme 1. The synthetic route of linear poly(PEGA-co-BPPA) and cyclic poly(PEGA-co-BPPA).

Figure 1. SEC curves of linear poly(PEGA-co-BPPA) (a) and cyclic poly(PEGA-co-BPPA) (b).

Figure 2. FT-IR spectra of linear poly(PEGA-co-BPPA) (a), linear poly(PEGA-co-BPPA)-N 3 (b), and cyclic poly(PEGA-co-BPPA) (c).

Figure 3. ${ }^{1}$ H-NMR spectra of linear poly(PEGA-co-BPPA) (a), linear poly(PEGA-co-BPPA)- $\mathrm{N}_{3}$ (b), and cyclic poly(PEGA-co-BPPA) (c) in $\mathrm{CDCl}_{3}$.

Figure 4. DLS results of the self-assemblies of linear poly(PEGA-co-BPPA) (a) and cyclic poly(PEGA-co-BPPA) (b) in the aqueous medium.

Figure 5. TEM images of the self-assemblies of linear poly(PEGA-co-BPPA) (a) and cyclic poly(PEGA-co-BPPA) (b) in the aqueous medium. Stained with phosphotungstic acid $(0.1 \mathrm{mg} / \mathrm{mL})$.

Figure 6. Photos and UV-Vis absorption spectra of (A) SWCNTs, L-copolymer/SWCNTs, C-copolymer/SWCNTs and (B) SWCNTs, L-copolymer assembly/SWCNTs, C-copolymer assembly/SWCNTs.

Figure 7. TEM images of SWCNTs (left), L-copolymer/SWCNTs (a), C-copolymer/SWCNTs (b), L-copolymer assembly/SWCNTs (c), and C-copolymer assembly/SWCNTs (d). Copolymers were stained with phosphotungstic acid (0.1 $\mathrm{mg} / \mathrm{mL})$.

Figure 8. AFM images of SWCNTs (left), L-copolymer/SWCNTs (a), C-copolymer/SWCNTs (b), L-copolymer assembly/SWCNTs (c), and C-copolymer assembly/SWCNTs (d).

Figure 9. Schematic illustration of two different assembly structures of cyclic 
poly(PEGA-co-BPPA) on the surface of SWCNTs. 

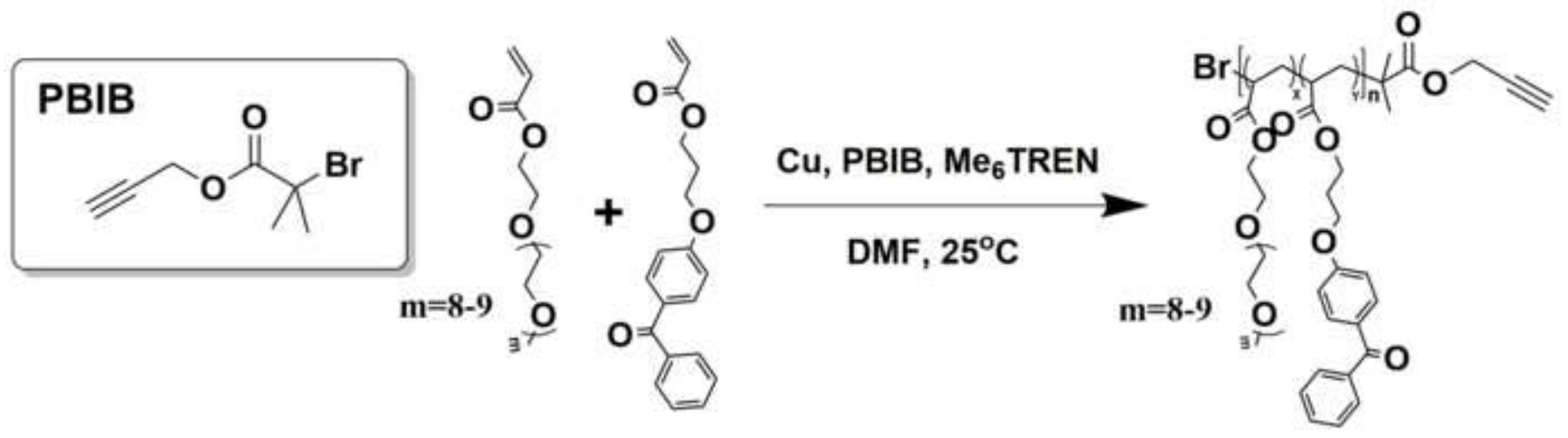

PEGA BPPA

linear poly(PEGA-co-BPPA)

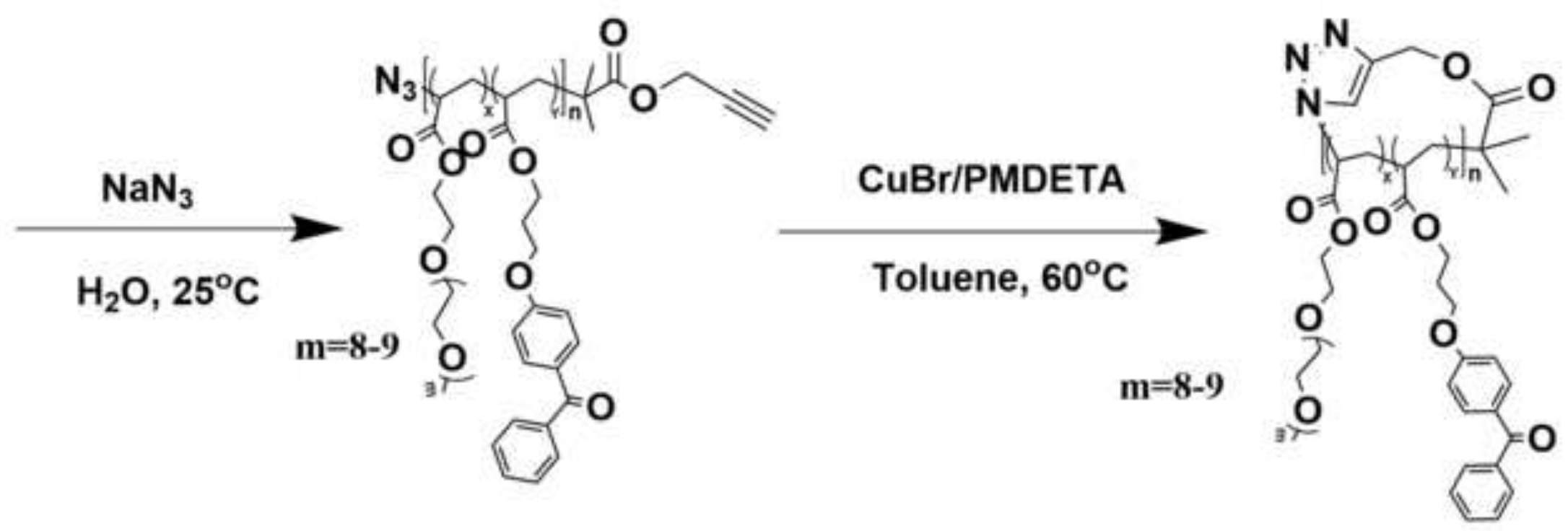

linear poly(PEGA-Co-BPPA)- $\mathrm{N}_{3}$

cyclic poly(PEGA-co-BPPA) 
(a) Ineor pohy(PECAce-EPPA)

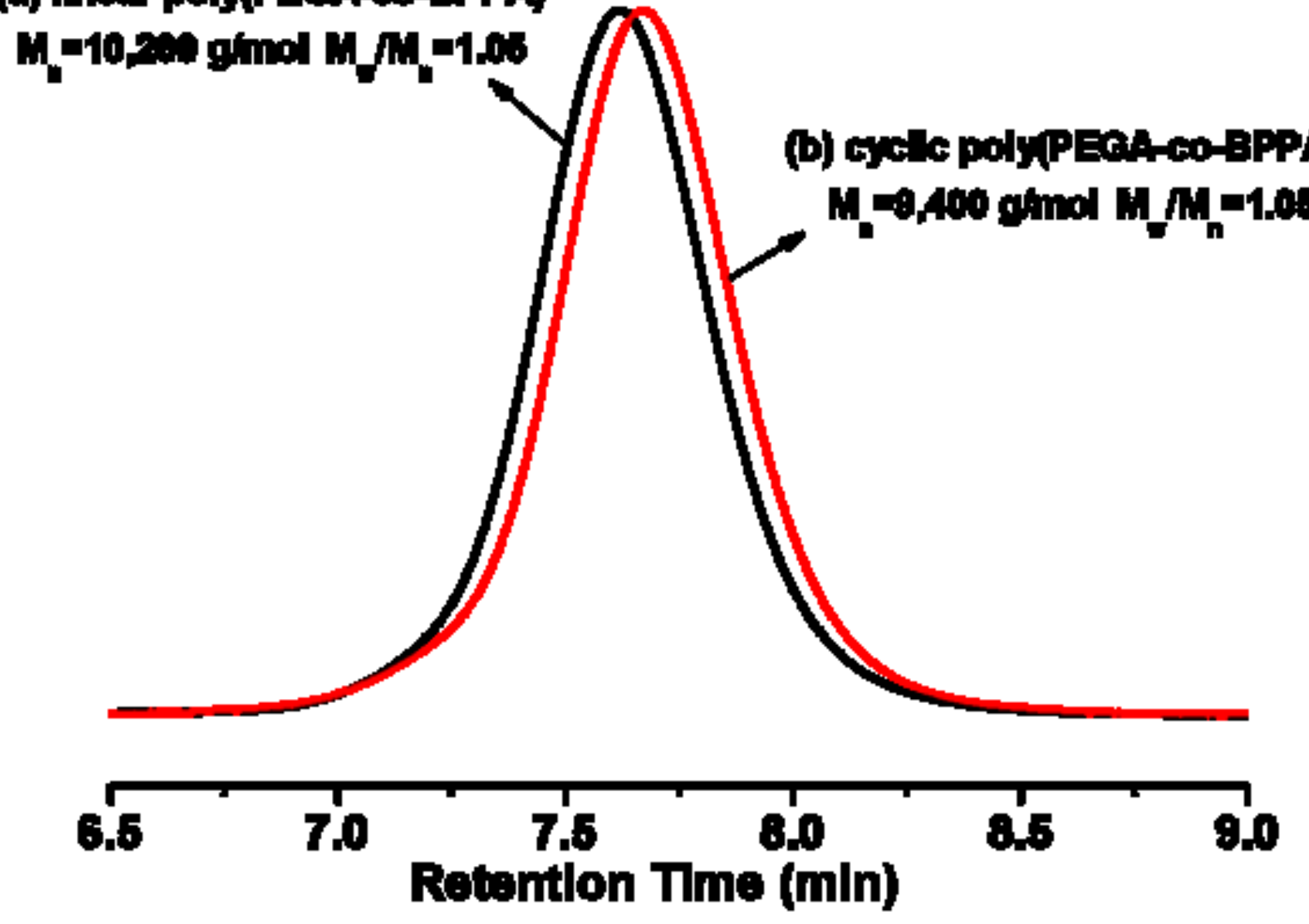


(a)

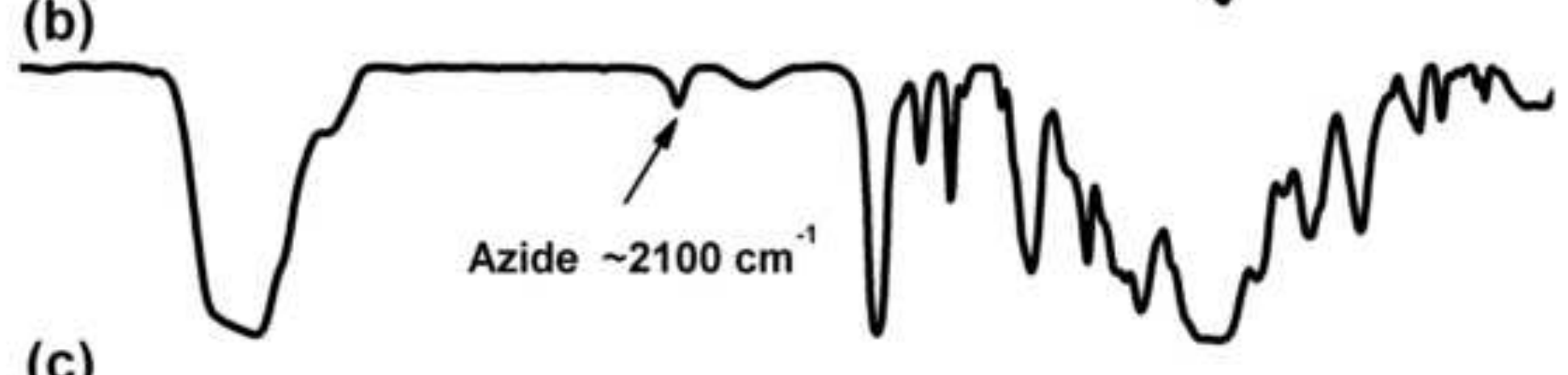

(c)
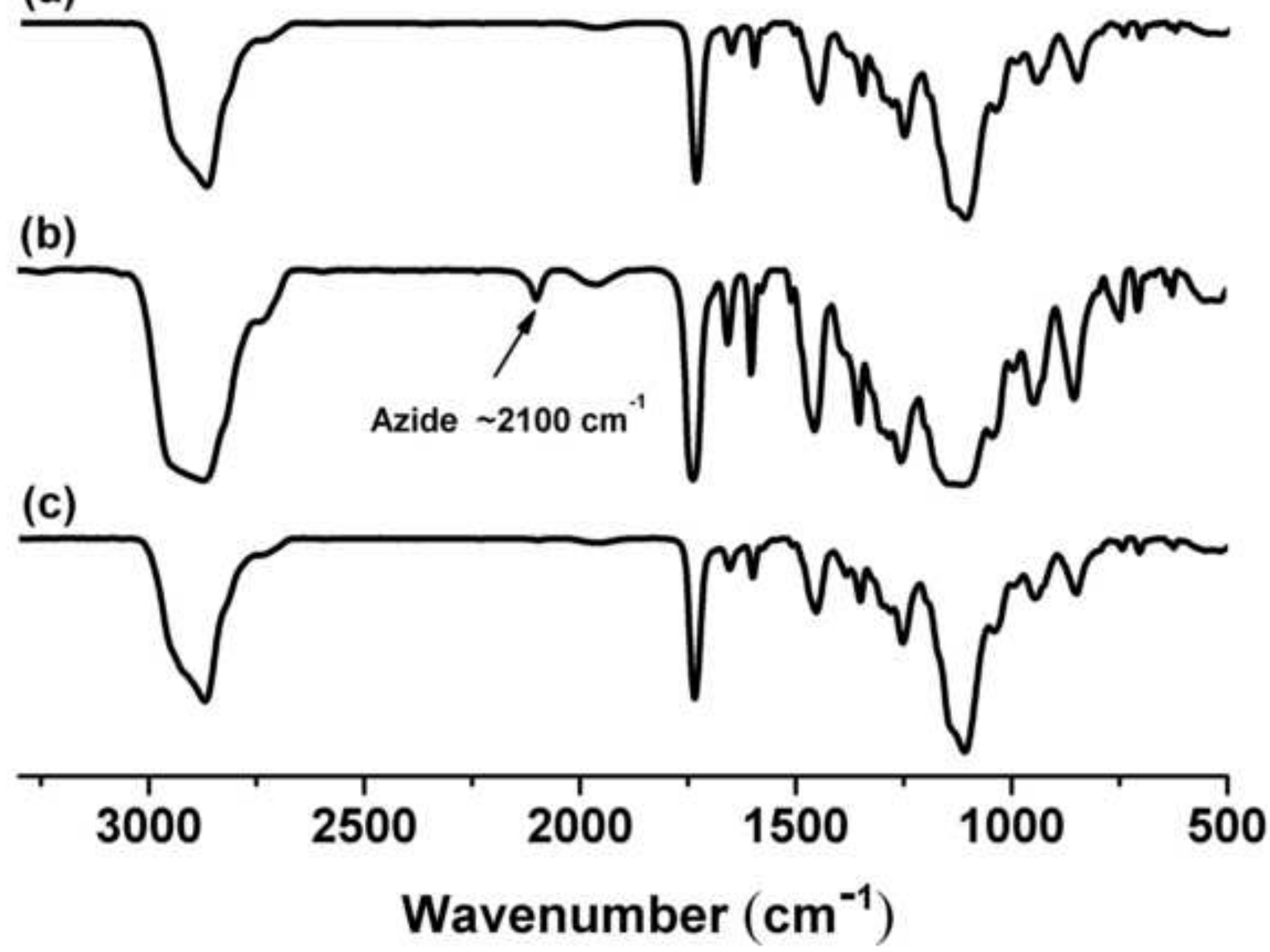


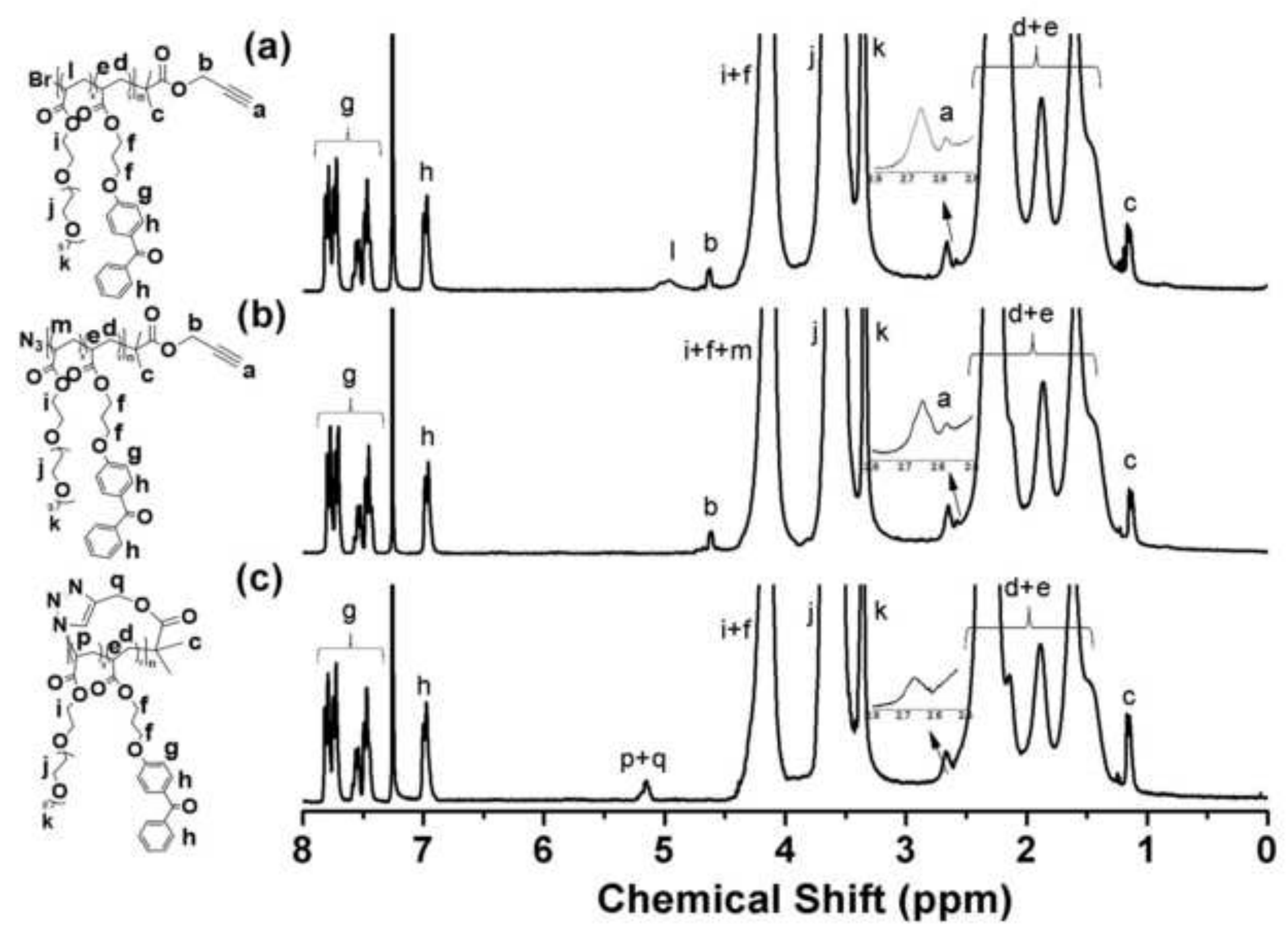




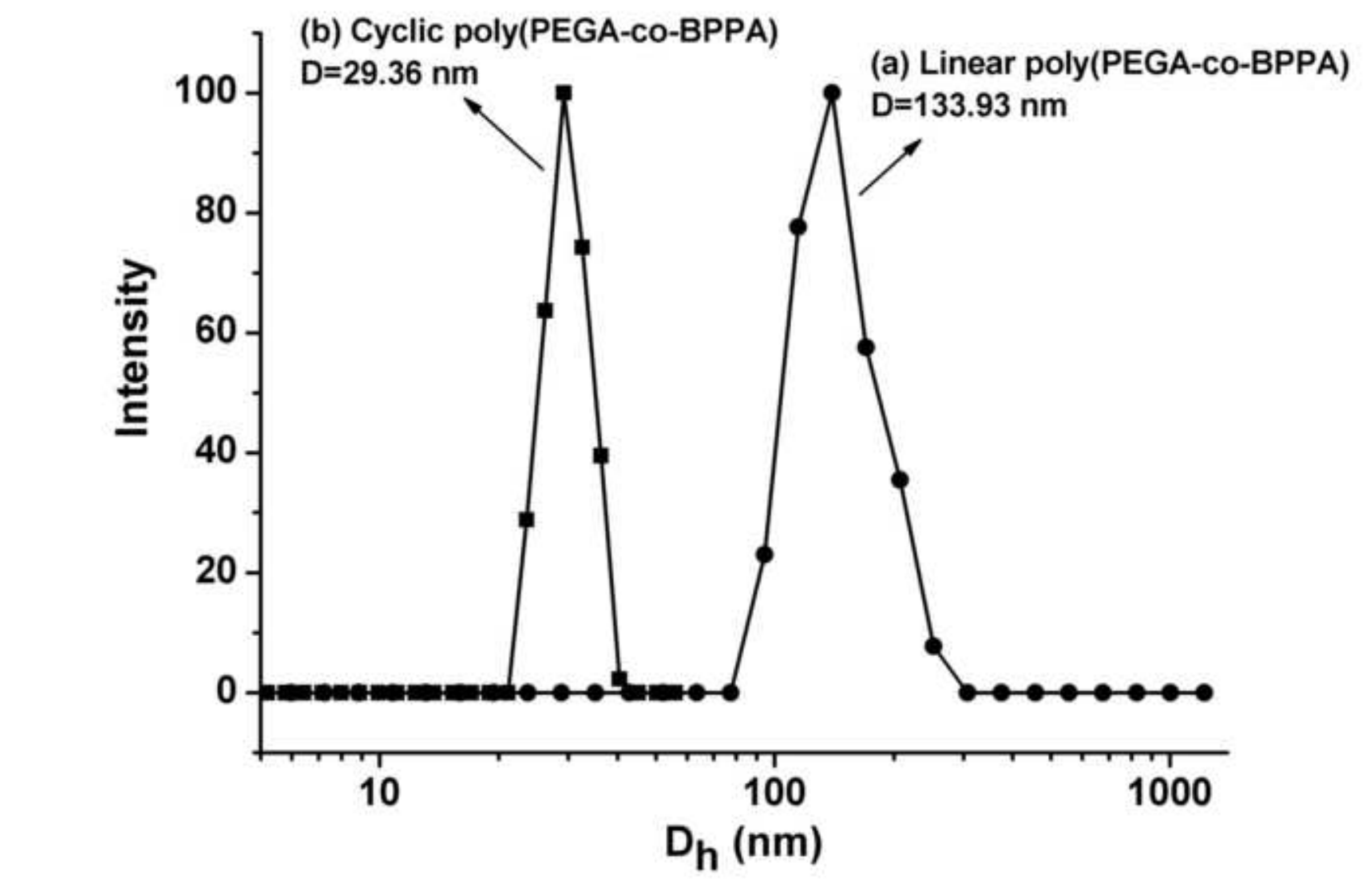




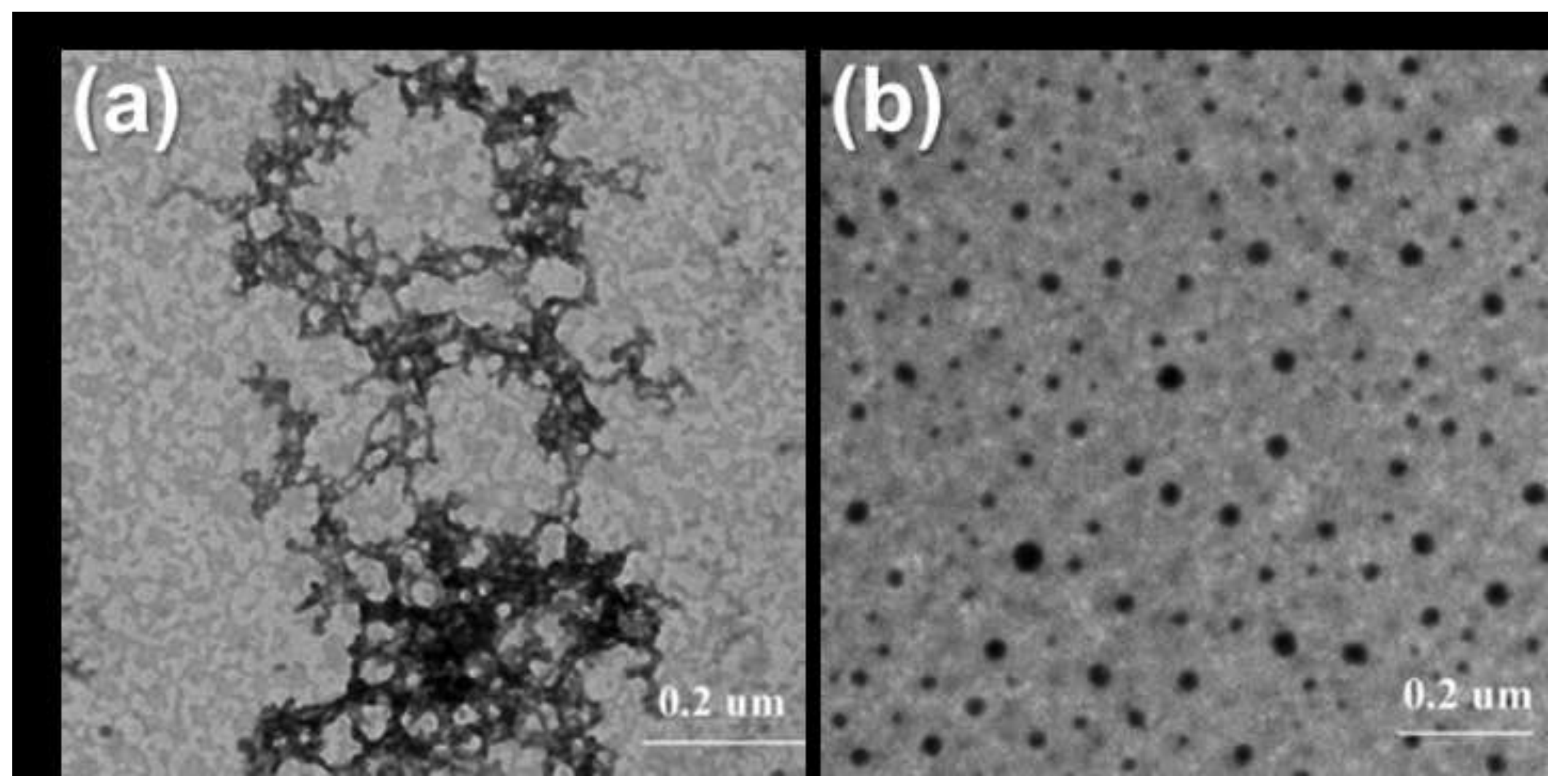


A
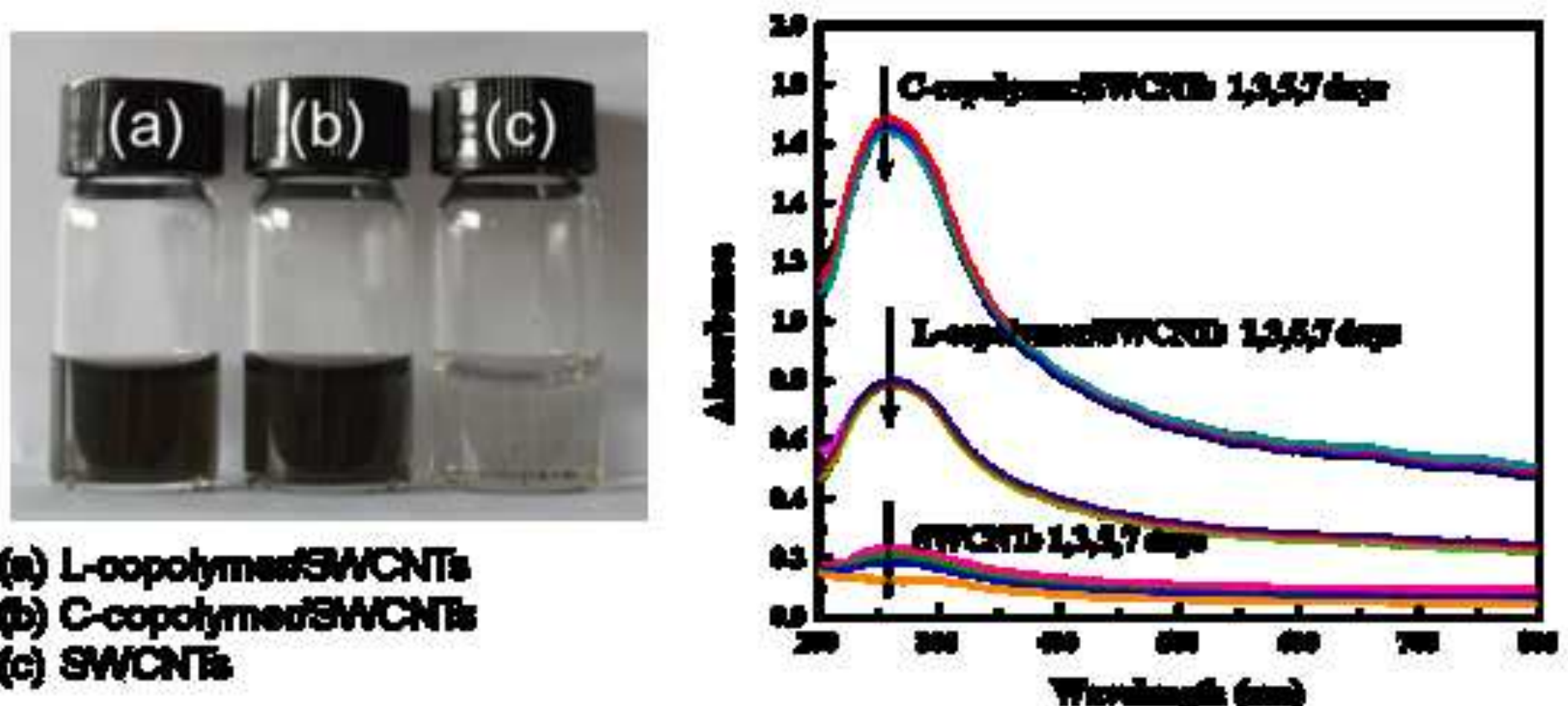

(i) L-oophymasucNTs

6) Copohmedisucut:

(어 ENCAT

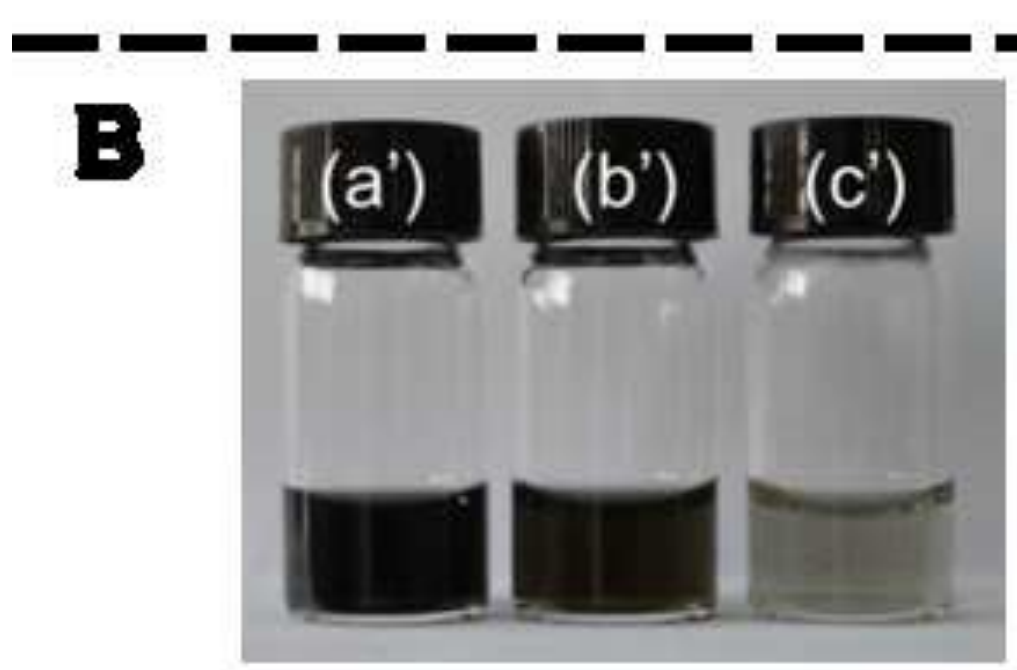

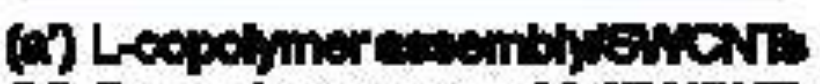

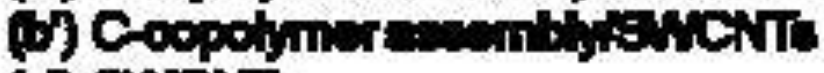
(o) ENickis

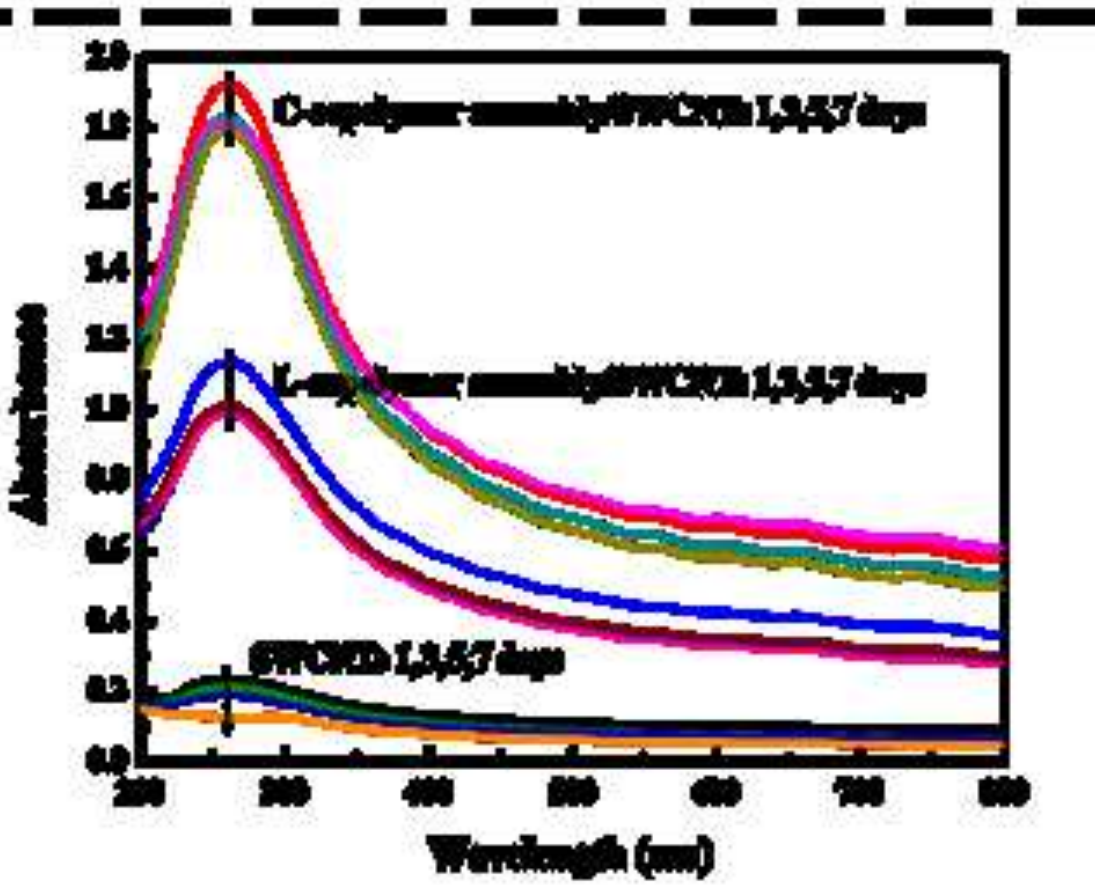




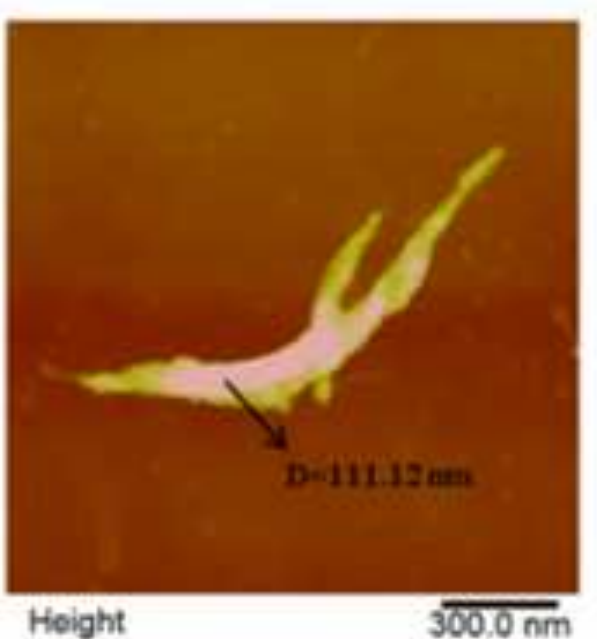

SWCNT

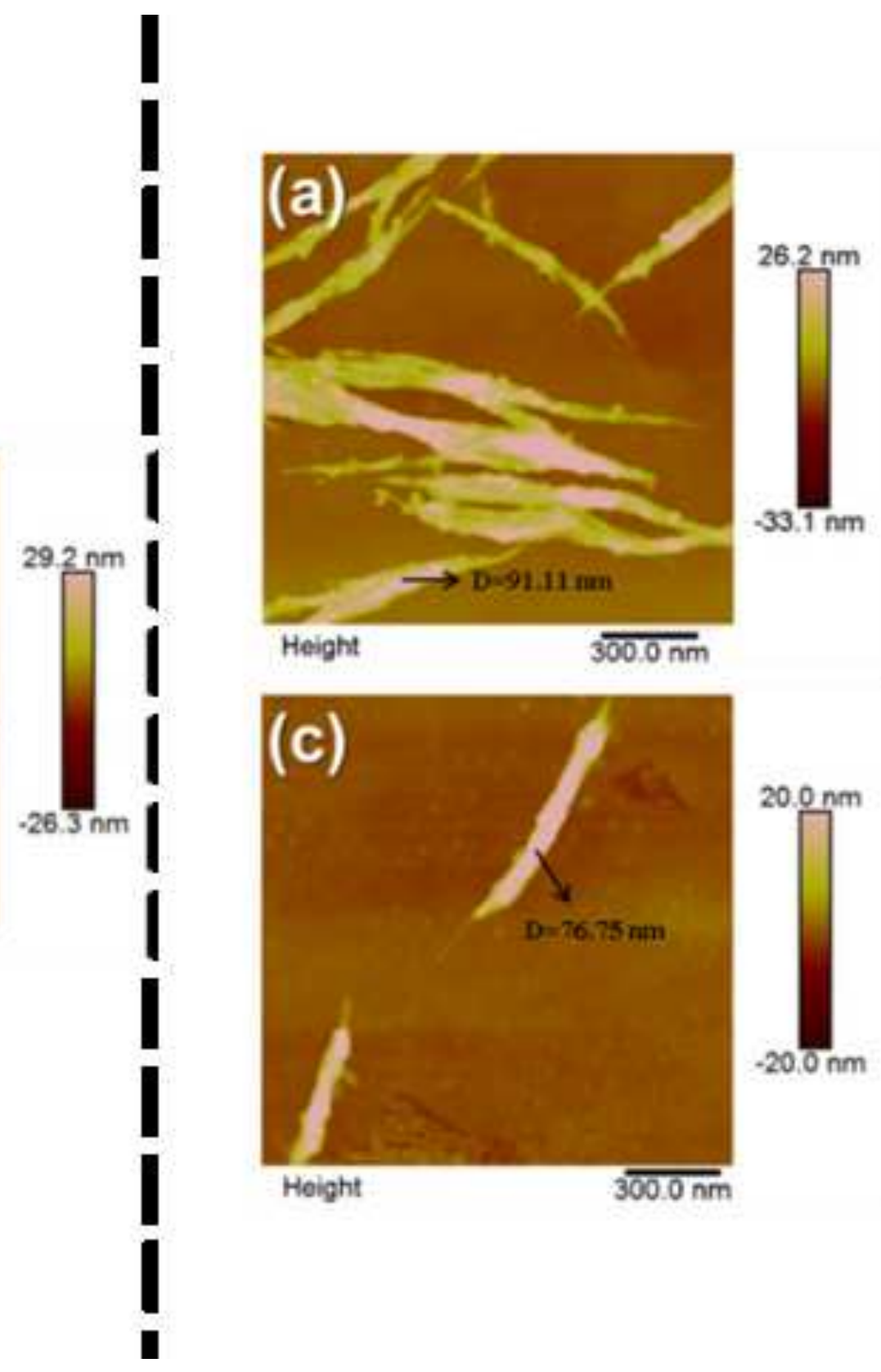

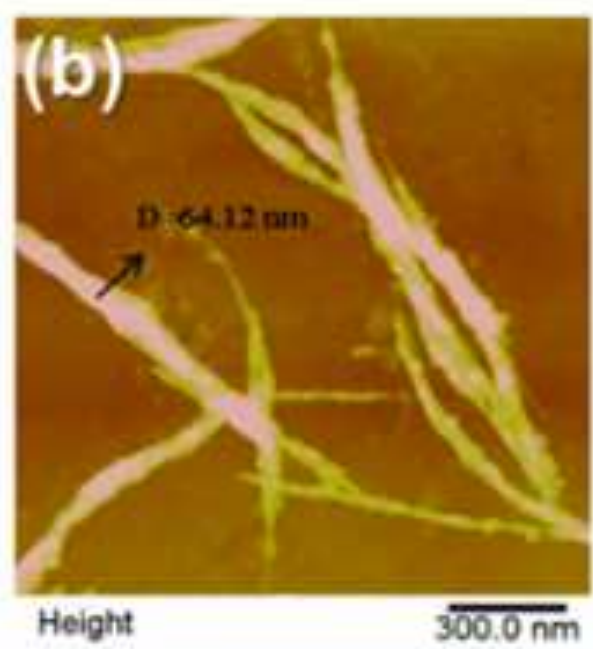
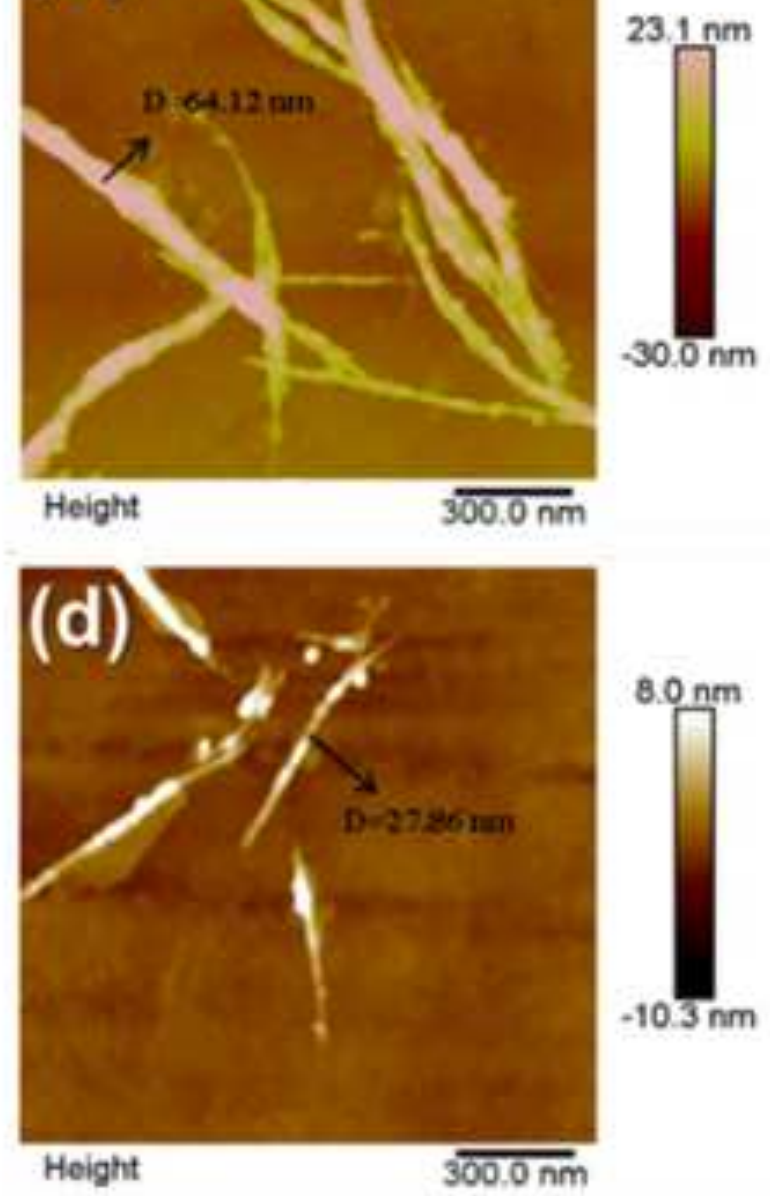

$-10.3 \mathrm{~nm}$

.

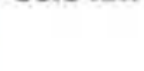




\section{(a) random adsorptlon}

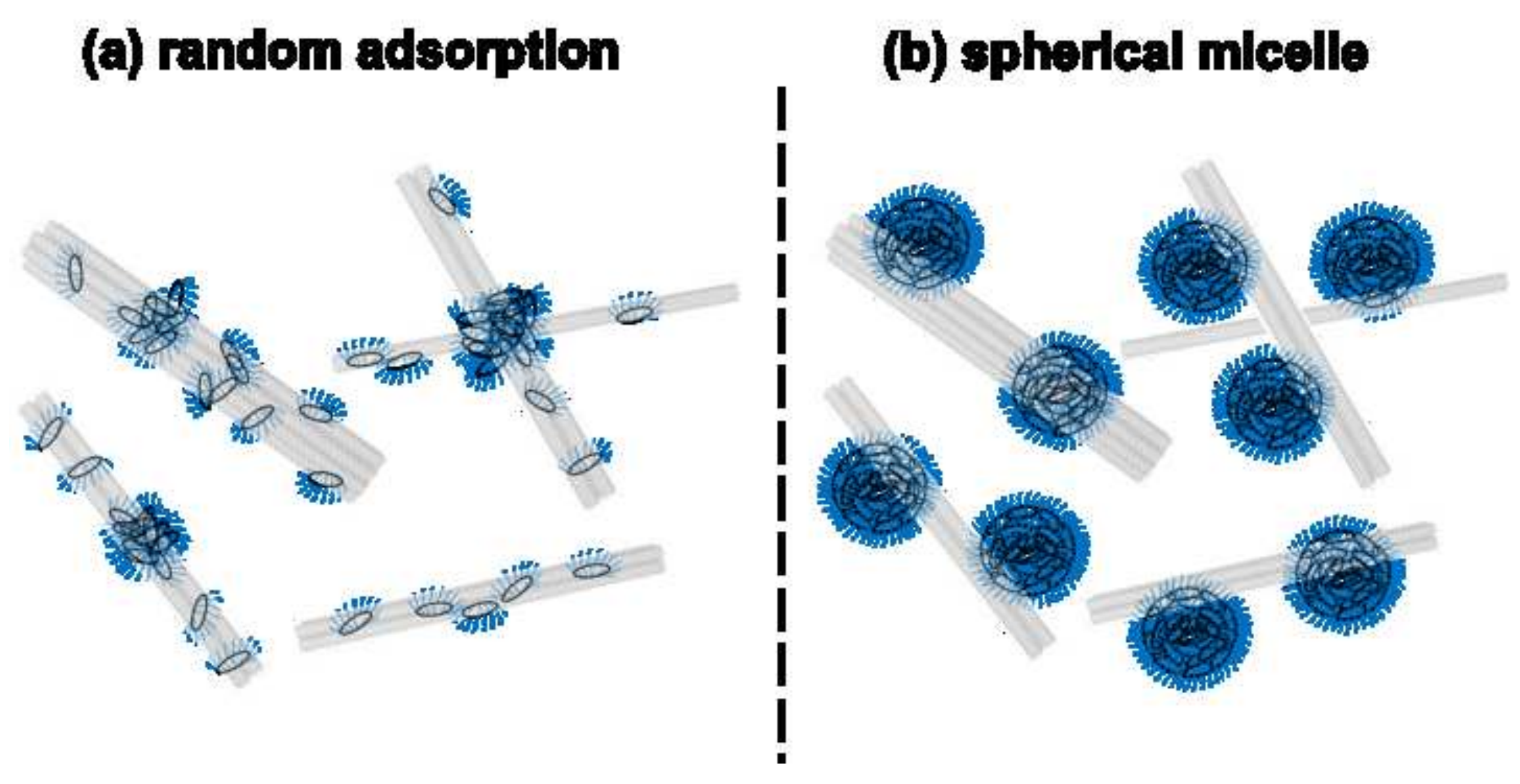

\section{(b) spherical mlcelle}

